\title{
Las dimensiones de la ciudadanía
}

\author{
Implicaciones teóricas y puesta en práctica
}

El análisis de la ciudadanía es crucial para calificar las transformaciones políticas en curso. En este artículo se realiza a dos niveles distintos: teórico y coyuntural. Bajo el primer aspecto se revisa tanto la literatura clásica como la más reciente acerca de su contenido conceptual en torno a ocho ejes predominantes y se evalúa la coherencia interna del modelo cívico.

El diagnóstico coyuntural del "clima" ciudadano mexicano se efectúa, por una parte, considerando sus manifestaciones principales de 1960 a la fecha y, por otra, caracterizando la respuesta dada a ellas por el gobierno a partir de los ochenta.

Juan Manuel Ramírez Sálz

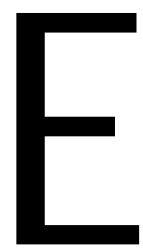

n los ensayos sociopolíticos mexicanos, las alusiones a la nueva cultura política, que está emergiendo en el país desde 1985, son frecuentes. Sin embargo, los esfuerzos canalizados a conceptualizarla e interpretarla están siendo mucho menos numerosos. Esta situación es más evidente en el caso de uno de los componentes de la cultura en cuestión: “Lo cívico o ciudadano". Tanto en sus versiones sustantivas (ciudadanía activa, ciudadanización, etcétera) como adjetivas (política, cultura, conciencia, insurgencia, prácticas, movimientos, etcétera, cívicos o ciudadanos), a este tópico se le ha dedicado escasa atención teórica. Mi interés en este ensayo no estriba tanto en considerar en qué consiste cada una de estas manifestaci ones (sustantivas o adjetivas) de la ciudadanía, cuanto en acotar su contenido conceptual. Para ello, en la primera parte reviso la literatura dásica sobre 
el tema y la más reciente, principalmente la europea. En el segundo inciso y a la luz del bagaje teórico previo, caracterizo las manifestaciones o experiencias mexicanas de la ciudadanía a partir de los sesenta. Finalmente considero la respuesta dada por el gobierno desde los ochenta a las diferentes expresiones ciudadanas. Por lo anterior, en este ensayo combino el planteamiento de tipo teórico con un diagnóstico preliminar acerca de la situación de la ciudadanía en el México contemporáneo, asunto que resulta crucial para calificar las transformaciones políticas en curso.

\section{La ciudadanía y sus elementos constitutivos}

El significado atribuido al término ciudadanía en los análisis acerca de la moderna sociedad civil, la transición democrática y la nueva cultura política, no es necesariamente coincidente. Por ello se impone precisar qué es un ciudadano o en qué consiste la ciudadanía.

A un primer nivel, se es ciudadano por el hecho de haber nacido en un determinado E stado-Nación. A partir de esta adscripción básica, el ciudadano adquiere los derechos y responsabilidades que en dicho país se reconocen. Por ello, la ciudadanía posee tanto un referente territorial, como jurídico y político. Pero la ciudadanía consiste, sobre todo, en una actitud o posición, es decir, la conciencia de pertenencia a una colectividad fundada sobre el derecho y la situación de ser miembro activo de una sociedad política independiente (Touraine, A., 1992, 381). Desde esta óptica, la ciudadanía significa fundamentalmente participación social e integración. Como consecuencia, ser ciudadano es sentirse responsable del buen funcionamiento de las instituciones que amparan los derechos en el país al que se pertenece. En este contexto, el ciudadano ideal es el que interviene en la vida pública y está dispuesto a someter su interés privado al interés general de la sociedad (B. van Steenbergen). Derechos y obligaciones son siempre correlativos.

Visualizada desde los derechos, "la ciudadanía -según Arendt- es el derecho a tener derechos, los cuales sólo es posible exigir a través del pleno acceso al orden jurídico que únicamente la ciudadanía concede" (Arendt, A., 1949). La relación entre derechos y ciudadanía es tal que, 
sin la conciencia de los primeros, no es posible la segunda. Frente a las concepciones y prácticas de las monarquías absolutas y de las dictaduras que consideran al hombre como objeto de gobierno, es decir, como súbdito en los gobiernos republicanos y democráticos, la ciudadanía estriba en val orarlo como sujeto de derechos. En consecuencia, ciudadano es quien conoce sus derechos y los defiende. La centralidad de los derechos es el asunto nodal de la sociedad civil y democrática (Cohen, J . Arato, A., 1993).

La relación existente entre ciudadanía y derechos puede ser visualizada desde diferentes ángulos. Una revisión de la literatura respectiva más importante permite destacar los siguientes aspectos: a) vinculación de la ciudadanía con las prácticas y luchas socio-políticas; b) reconocimiento de derechos y tipos de ciudadanía; c) ciudadanía y tradiciones ideológicas; d) ciudadanía e igualdad; e) derecho a la diferencia; f) las vertientes local y mundial de la ciudadanía, y g) ejercicio de los derechos y actitudes a asumir ante el Estado. A continuación asiento el estado de la cuestión respecto a estos tópicos.

\subsection{Ciudadanía y prácticas socio-políticas}

Sobre este tema, H. A. Giroux, desde una óptica marxista, ha enfatizado que el reconocimi ento de los derechos debe ser ubicado en el contexto histórico de las luchas sociales. En sus propios términos: "Ciudadano es algo más que un simple portador de derechos, privilegios e inmunidades abstractos... No se puede definir la ciudadanía dentro de un vacío político, de una amnesia histórica que se caracteriza por un silencio intencional respecto a las constantes luchas históricas que se han librado en cuando al significado y a las potencialidades no realizadas que subyacen a los distintos conceptos de ciudadanía" (Giroux, H.A., 1993, 17 y 143). De acuerdo con este juicio, las prácticas emancipatorias de los ciudadanos son las que explican la promulgación de los derechos. Analizando la situación respectiva de la Inglaterra de los siglos XVII a XIX, Somers es más explícito al señalar que la ciudadanía no constituye un cuerpo de derechos universales y de deberes, sino que es la resultante de un proceso que se desarrolló a través de un conjunto de prácticas 
sociales enclavadas institucionalmente. EI proceso institucional que explica los derechos ciudadanos está constituido por las relaciones entre las esferas públicas, la vida asociativa de la comunidad y los patrones de cultura política. Por ello, la ciudadanía no fue concedida como un derecho; fue creada por las actividades de los pueblos en situaciones particulares que interactuaron con instituciones, ideales y reglas del poder legal y la participación gubernamental (Somers, M. R., 1993, 609, 611 y 612). Es decir, la capacidad asociativa de los ciudadanos, su participación en la esfera pública y el recurso hábil a las leyes para convertirlas en derechos son los factores explicativos de las formas que asumió la ciudadanía en Inglaterra.

\subsection{Relación entre tipos de derechos y modalidades de la ciudadanía}

Los aportes de T. H. Marschall son dásicos y aclaratorios sobre este tópico. Este autor define la ciudadanía como un "status que implica el acceso a varios derechos" (Marschall, T. H., 1976, IX). Además ha establecido la concatenación que se ha dado entre el reconocimiento histórico de los derechos y la aparición de los tipos o varios rostros de la ciudadanía.

Según su perspectiva, en el siglo XVII se reconocieron los derechos civiles: igualdad ante la ley, libertad de la persona, libertad de palabra, pensamiento y culto, el derecho de propiedad y de concluir contratos. Estos derechos del individuo dieron origen a la ciudadanía civil. El siglo XIX vio el desarrollo de los derechos políticos: el de asociación y el de participación en el ejercicio del poder político como miembro de un cuerpo investido con autoridad política (asambleas legislativas o cámaras) o como elector de los miembros de ese cuerpo. Tales derechos constituyen la ciudadanía política. Finalmente el ejercicio de los derechos políticos en el siglo XX produjo derechos sociales: el de un cierto nivel de bienestar económico y social (vivienda, educación, salud, etcétera) y el compartir plenamente el legado social, acorde con los estándares prevalecientes en la sociedad.

De acuerdo con este planteamiento, de la toma de conciencia acerca de cada uno de estos derechos emergió la modalidad de ciudadanía 
correspondiente. Ésta es la explicación de que la ciudadanía tenga tres dimensiones: la civil, la política y la social.

En la valoración actual de la ciudadanía, tiende a rel egarse esta perspectiva histórica; y asimismo a privilegiarse la ciudadanía política sobre la civil y la social, desconociendo que las tres modalidades son igualmente constitutivas de ella.

Estos diferentes derechos y los tipos de ciudadanía correspondientes no sól o constituyen un modelo ideal de relaciones sociopolíticas. Se sustentan en sendas instituciones y normatividades que fueron creadas para ampararlos y darles materialización. A los derechos civiles responden Ios tribunales; a los políticos, los cuerpos políticos representativos; y a los sociales y económicos, los servicios de seguridad social y las escuelas principalmente.

\subsection{Ciudadanía y tradiciones ideológicas}

Frecuentemente suele olvidarse que a las tres dimensiones de la ciudadanía, recién aludidas, subyacen tres posiciones ideológicas diferentes $y$, en algunos aspectos, encontradas. De acuerdo con el propio Marschall y F. Escalante, la que corresponde a cada uno de los tres tipos de derecho es la siguiente. En el reconocimiento de los derechos civiles estuvieron presentes convicciones liberales que enfatizaban el aspecto personal o individualista de la ciudadanía. Ellas afirmaron los derechos del individuo ante el Estado absolutista, así como ante la presión que ejercían las formas tradicionales de vinculación social, tales como las comunidades, gremios y mayorazgos. Esta tradición privilegió la defensa de las garantías individuales, la tolerancia y la necesidad de respetar el orden jurídico. Su principal reclamo y meta políticos eran limitar el poder y la acción de gobierno. (Escalante, F., 1992, 33). La ciudadanía civil, fundamentada en esta tradición, fue impulsada por la Revolución Francesa y resultó ampliamente funcional a los intereses del capitalismo concurrencial. Por su carácter individualista, no necesariamente se vinculó con la democracia ni con la dimensión del bienestar social. Por su parte, la ciudadanía política está articulada a la tradición republicana y democrática del siglo XIX y a su defensa de la participación política 
y del sufragio en particular. Esta tradición "exige la participación, la justicia y el autogobierno" (E scalante, F., 1992, 34). No enfatizó el ámbito privado o las libertades individuales. Y se fundamentó en la soberanía popular. Finalmente la ciudadanía social se nutre de tres fuentes ideológicas distintas: el socialismo (no necesariamente marxista), la doctrina social de la Iglesia y el keynesianismo, las cuales subrayan la necesidad del sentido comunitario y el bienestar social. Bajo este aspecto, no coinciden con las posiciones individualistas liberales. Pero no exigen forzosamente la participación política democrática (Escalante, F., 1992).

Actualmente se tiende a desdibujar el interjuego existente entre estas tres diferentes tradiciones que, a primera vista, resultan difíciles de conciliar. Ellas impulsaron por separado en el surgimiento de los derechos ciudadanos respectivos. $Y$ hoy coexisten, no sin tensiones, dentro del cuerpo de normas y valores públicos denomi nado "model o cívico".

\subsection{Ciudadanía e igualdad}

Respecto a este asunto, Lipset resalta que "el aspecto más importante del concepto de ciudadanía es la asunción de la igualdad respecto a los derechos y deberes". Según este autor, "el carácter revolucionario de la ciudadanía es la creación de un status en el que los hombres son iguales" (Lipset, S.M., 1976, X). Al respecto, Lafer, parafraseando a Arendt, recuerda que "no nacemos iguales. Nos volvemos iguales como mi embros de una colectividad en virtud de una decisión conjunta que garantiza a todos derechos iguales. La igualdad no es algo dado... Es una construcción elaborada convencional mente por la acción conjunta de los hombres a través de la ley y de la organización de la comunidad política" (Lafer, C., 1994, 172). Sin embargo, se corre el peligro de silenciar que, a pesar de que la ciudadanía tiene una connotación de integración, su base está formada por una sociedad desigual y excluyente. Por ello, A. Borón insiste en no dejar en segundo plano los diferentes grados en que se materializan las tres dimensiones de la ciudadanía. Ello es particularmente notable entre la vertiente política y la social. La primera de 
ellas establece una igual dad entre los ciudadanos de carácter políticoformal ante la ley, mientras que en la concreción de la ciudadanía social se advierten notorias desigualdades materiales en los niveles de vida de los ciudadanos. Es decir, la ciudadanía política puede ir acompañada de des-ciudadanía social y económica. $\mathrm{O}$, en otros términos, los predicados igualitaristas en el terreno político no se cumplen en el socio-económico. Ello implica despojar a la ciudadanía de las mayorías de contenidos de dignidad y eficacia (Borón, A. A., 1993). Por lo anterior, habría que reconocer que la ciudadanía intenta contrarrestar las desigualdades sociales en función de los mismos derechos básicos. Pero igualmente es obligado admitir que existe todavía una notable distancia entre la ciudadanía formal o institucional y la sustancial o real.

\subsection{El derecho a la diferencia}

La insistencia en la contradicción existente entre igualdad formal y desigualdad real no debe llevar a relegar u opacar otra dimensión de la ciudadanía. Ésta consiste en el derecho civil a la diferencia, es decir, a la individualidad y diferenciación o, en otros términos, a lo propio o distintivo. En un contexto globalizante, homogeneizador y anulador de las particularidades de los países, regiones y grupos, es importante subrayar esta vertiente ciudadana. En el terreno socio-político, este derecho es particularmente importante para salvaguardar la existencia, reconocimiento y demandas de las minorías (marginadas o no social, cultural y políticamente). Pero el derecho a la diferencia no consiste sólo en una defensa ante lo ajeno o extraño amenazantes, sino, sobre todo, en la afirmación de lo constitutivo y diferenciante. R. Rosal do insiste en esta dimensión que califica de "ciudadanía cultural".

\subsection{La ciudadanía “local”}

Como sostiene Marschall, la ciudadanía es por principio nacional (Marschall, 1976, 72). Por ello, las concepciones clásicas de la ciudadanía la vinculan con una comunidad y un Estadonacionales (C. J . Moulin, R. Bendix). Se trata, por tanto, de visiones nacionales de la ciudadanía. 
Porque la nación es el soporte de toda soberanía y ciudadanía (J -F. Lyotard, 1991). En este contexto, hablar de ciudadanía local constituye un contrasentido. Sin embargo, en la literatura sobre movimientos sociales, especialmente los urbanos, es frecuente el uso de este término. Su sentido está relacionado con lo que comentaré más adelante (\#2.3.) acerca de la distinción entre ciudadanía "primaria" y "secundaria". Más específicamente alude al derecho a intervenir en las decisiones sobre la ciudad, como ámbito particular de la materialización de la participación ciudadana (E. J elin, L. Kowarick, M. Schteingart). Bajo este aspecto, la ciudadanía local consiste en una modalidad de la ciudadanía o de los derechos políticos. $Y$, en este sentido, no se contrapone a la dimensión nacional de la ciudadanía.

\subsection{Ciudadanía "mundial"}

En el extremo contrario a lo comentado acerca de la ciudadanía local, es obligado aludir a varios hechos de orden filosófico y político que permiten sostener su carácter multinacional y mundial (N. Arendt, J . Habermas, R. Falk, B. van Steenbergen y B. Turner).

Históricamente, los primeros compendios ordenados de los derechos humanos se referían al ser humano como individuo, en su mera condición de hombre, como titular de derechos y obligaciones no otorgados ni otorgables por el gobernante y, en consecuencia, independientes del Estado-Nación al que esté adscrito. Estos derechos nacen, crecen y se desarrollan con la humanidad. Y, por ello, deben ser considerados como exigibles universalmente (J . Madrazo y W. Beller, 199 y 211). Por otra parte, las diferentes dedaraciones contemporáneas de los derechos del hombre y del ciudadano sostienen que le corresponden por ser miembro de la familia humana y ciudadano del mundo (ONU, Declaraciones de 1948, 1960 y 1976). Asimismo, la experiencia de la integración europea ha sentado antecedentes para el reconocimiento de una nacionalidad y derechos comunes a los ciudadanos de los diferentes países que la integran. Finalmente, según I. Wallerstein, S. Amin y M. Lasime, Ias prácticas de los sindicatos internacionales y federaciones mundiales de trabajadores, así como de los partidos mundial es e igual mente de las 
federaciones internacionales de movimientos sociales como los ecologistas y de pobladores, sentarían las bases y aspiraciones del ciudadano universal y de la "sociedad civil mundial".

\subsection{Ciudadanía y actitudes ante el Estado}

Los análisis de J. M. Barbalet acerca de las posiciones que los ciudadanos deben asumir ante el Estado, para la materialización de los diferentes derechos, son particularmente esclarecedores. Al respecto ha de resaltarse que los derechos civiles son derechos contra el Estado, mientras que los derechos sociales constituyen reclamos garantizables por él. En el primer caso, es decir, para que las personas puedan operar como ciudadanos, deben existir libertades que el Estado no puede invadir y, por ello, acciones que éste no puede ejecutar; en otros términos, para que la sociedad civil actúe ciudadanamente, el Estado no debe intervenir. Por el contrario, éste tiene que respetar el campo de actuación de la sociedad civil. Lo opuesto sucede con los derechos sociales. Puesto que éstos cubren aspectos relacionados con el bienestar (educación, salud, vivienda, etcétera), para que los ciudadanos puedan acceder a estos bienes, el Estado ha de establecer las diferentes condiciones (legales, administrativas, institucionales, etcétera) que permitan su materialización. Ésta es la razón de que el Estado esté obligado a realizar ciertas acciones específicas; es decir, debe actuar e intervenir directamente. En consecuencia, las actitudes de la ciudadanía ante estas dos formas de acción estatales en el campo de los derechos han de ser distintas. Ciertamente, en ambos casos los ciudadanos se asumen como fundamento del poder y con derechos ante el Estado. Pero respecto a los derechos civiles y políticos, el diálogo entre ciudadanos y Estado se establece en éstos o similares términos: "Te exigimos que respetes el ámbito de acción propia e independiente de la sociedad y no interfieras en el ejercicio de nuestros derechos". Por el contrario, en el caso de los derechos social es y económicos, la interlocución se realiza en esta otra línea: "Te exigimos que crees las condiciones objetivas y suficientes para que estos derechos no constituyan meras dedaraciones, sino que, por el contrario, puedan materializarse para todos y cada uno de los ciudada- 
nos". Como es claro, estos dos reclamos ciudadanos hacia el gobierno difieren fundamentalmente entre sí.

\section{9. ¿Es coherente el modelo cívico?}

Los ocho aspectos reseñados de la ciudadanía (reconocimiento progresivo, dimensiones implicadas, corrientes ideológicas subyacientes, igualdad propugnada, derecho a la diferencia, vertientes local y mundial y roles diferentes exigidos ante el Estado) constituyen puntos nodales de la discusión acerca de este tópico. Las vinculaciones entre ellos parecen lógicas en ciertos casos. En otros, la conexión no es evidente a primera vista. $Y$, por otra parte, obligan a plantear interrogantes acerca de aspectos que quedan todavía abiertos a la discusión.

Del primer tipo es la conexión real que se ha dado entre las luchas socio-políticas (que crearon las condiciones para el reconocimiento de los derechos ciudadanos) y las actitudes distintas que, una vez aceptados, exigen de los ciudadanos para que puedan materializarse, según sea el caso, a través de la intervención, o ausencia de ella, por parte del Estado.

Asimismo es convincente plantear y recordar que los derechos ciudadanos no constituyen un cuerpo unitario (que hubiera sido aceptado por los Estados en un único acto de reconocimiento y se nos hubiera legado en bloque), sino que tuvieron un desarrollo desigual que se llevó a cabo en distintos momentos de la historia social y política de las diferentes naciones.

Sin embargo, resulta menos dara la articulación o coexistencia entre las diferentes corrientes ideológicas en que se fundamentaron los distintos tipos de derechos y aspectos de la ciudadanía. ¿Son realmente compatibles el liberalismo con la democracia y el socialismo? ¿Cuál es el saldo social de las experiencias liberales de la ciudadanía? Por otra parte, ¿cómo sostener la validez y vigencia de la igualdad entre los ciudadanos frente a condiciones de vida profundamente desigual es y excluyentes? Ello obliga a reconocer que la ciudadanía igualitaria constituye un modelo, un ideal y una meta en buena parte no alcanzados. A propósito de este "modelo cívico" que subyace a la concepción de la ciudadanía, F. Escalante sostiene que confunde las tradiciones implíci- 
tas en él (la republicana, la liberal y la democrática) en una fórmula más bien imprecisa. Sin embargo, las contradicciones no pueden el iminarse: se podría decir que forman el corazón del modelo de moral pública y de las formas de organización política de los últimos dos siglos (E scalante, 1992, 32 y 35).

Otro aspecto que pareciera cuestionar el valor heurístico del concepto de ciudadanía es el hecho de que se aplique a niveles o realidades muy distintas, como la local, nacional y mundial. Como ya se aclaró, la contradicción entre la ciudadanía local y la nacional es más aparente que real, ya que la primera no constituye más que una particularización de la segunda a un ámbito espacial específico. Este acotamiento espacial no modifica la referencia al Estado nacional correspondiente. Sin embargo, la consistencia del término "ciudadanía mundial" parecería problemática porque remite a un Estado global o mundial inexistente. Como es sabido, la constitución de este tipo de Estado fue la aspiración de los 51 países fundadores de las Naciones Unidas en 1945. De hecho, uno de los fundamentos de la ciudadanía "mundial" consiste en el reconocimiento que dichos Estados otorgan a un conjunto de derechos que se comprometen a respetar. Pero además los avances logrados por parte de la ONU y las experiencias de los sindicatos, partidos y movimientos sociales en este terreno apuntan hacia un proyecto político deseable y que se está materializando progresivamente. Para respaldar la ciudadanía mundial está en proceso de constitución la conciencia de pertenencia a una sociedad internacional y de estar, cada vez más intensamente, inmersos en relaciones políticas que rebasan los límites nacionales.

Y de entre las preguntas que provoca la conceptualización realizada acerca de la ciudadanía, dos parecen centrales: 1) ¿es posible reconocer nuevos derechos $y$, en esa medida, ampliar las dimensiones de la ciudadanía?, y 2) ¿tiene la ciudadanía necesariamente una vertiente individual o caben expresiones colectivas de ella?

Respecto de la primera pregunta, es difícil aceptar que el reconocimiento de derechos y la creación de nuevas formas de ciudadanía constituyan procesos ya terminados. Con base en los análisis de Marschall y Somers acerca de sus factores explicativos (participación en la esfera 
pública, vida asociativa de los grupos, innovaciones en la cultura política y recurso a las leyes para convertirlas en derechos), cabe plantear la posibilidad de creatividad en ambos terrenos. De hecho, en la literatura más reciente se sostiene la existencia de derechos culturales y ecológicos, así como de las ciudadanías correspondientes (B. van Steenbergen). La problemática ambiental o ecológica es actualmente planteada como una cuestión del habitat humano o del planeta como un todo (Conferencia de Naciones U nidas en Río de J aneiro, en 1992). Bajo este aspecto posee una relación directa con la ciudadanía mundial. Los hombres se descubren crecientemente como parte de la naturaleza, responsables (no dueños) de la tierra y con derecho a un desarrollo sustentable y a un ambiente vivo. Por su parte, la dimensión cultural de la ciudadanía enfatiza las prácticas sociales que permiten la participación, a un mismo tiempo, en la definición y orientación de la cultura nacional, así como en la globalización o mercado mundial de bienes culturales. De esta manera se rescata simultáneamente el derecho a la diferencia o heterogenei dad (contra las tendencias estandarizantes) y a la inclusión (frente a las prácticas excluyentes). Finalmente es obligado reconocer que la caracterización de la ciudadanía realizada hasta ahora en este ensayo transmite la experiencia de los países capitalistas centrales y los enfoques preval ecientes en la literatura socio-política respectiva. E I más elemental sentido histórico y crítico obliga a no atribuir patente de corso a esta versión particular de la ciudadanía y a preguntarse cuáles han sido los términos en que México ha transitado por este camino. Bajo este supuesto, responderé en el inciso siguiente a la pregunta acerca de las posibles expresiones colectivas de la ciudadanía.

\section{Cinco experiencias mexicanas de la ciudadanía}

En los acercamientos mexicanos al tema de la ciudadanía destacan cuatro ejes temáticos. Por una parte, son importantes los análisis acerca de las aportaciones del liberalismo del siglo XIX a la ciudadanía civil (J . Reyes Heroles, A. villegas y G. F. Escal ante). Por otra, se ha insistido en los avances que implicó la constitución de 1927 en el reconocimiento de los derechos sociales y económicos (D. Valadés). Asimismo, varios 
autores han reconocido los logros obtenidos en este terreno por los movimientos sociales y políticos, e ind uso revolucionarios y guerrilleros (R. García R., J . Madrazo C. y W. Beller T.). Sin embargo, los ensayos acerca de la evolución posterior del país en este campo coinciden en reconocer el escaso desarrollo de la sociedad civil y de los derechos cívicos y políticos. Por ello es importante reconstruir, así sea esquemáticamente, las principal es expresiones mexicanas de la ciudadanía a partir de los sesenta y en el terreno cívico, social y político. Al respecto se detectan, al menos, cinco experiencias significativas. Éstas son: a) los grupos "cívicos o ciudadanos semipartidarios; b) los comités cívicos del movimiento campesino guerrerense y su expresión protopartidaria; c) la ciudadanía lograda por los movimientos reivindicativos; d) el movimiento por los derechos humanos, y e) la emergencia ciudadana de la última década. A continuación aporto un bosquejo de cada uno de ellos.

\subsection{Los grupos "cívicos" semipartidarios}

Hasta muy recientemente, se consideraban como cívicos los agrupamientos constituidos por activistas que actuaban formalmente fuera de las estructuras partidarias, pero cuyos núcleos eran, de hecho, prolongación de ellas. Constituían el brazo "civil" de los partidos. Eran expresiones organizadas de tipo político que no asumían la forma de partido. Una de sus modalidades actuales fueron los "comités ciudadanos pro Cárdenas", los cuales constituían un recurso para insertar a ciudadanos en intereses y proyectos partidarios (PRD, 1994). Algunos analistas los han visualizado como medio para recuperar a ex-perredistas o como perredistas disfrazados de ciudadanos. En cualquier caso, se trataría de una expresión "Iight" del PRD. Este juicio sería extrapolable a la resolución de reservar la mitad de sus postulaciones a cargos de elección popular a los calificados por este partido como "candidatos externos", es decir, a ciudadanos sin partido para que fueran diputados por ese instituto político. Como es claro, la incorporación de ciudadanos independientes a cargos de representación popular rompería el monopolio de las funciones públicas por parte de miembros de partidos y contribuiría a la ciudadanización de la política y de la vida pública. Pero 
no niega que el ciudadano que hipotéticamente lograra desempeñar ese cargo, además de ser entonces funcionario público, se atendría a los lineamientos del partido que lo postuló; es decir, tendería a actuar como miembro de su bancada. Ésta fue, al menos, la experiencia de los diputados ciudadanos de la anterior legislatura por parte del PAN, misma que intenta ser superada ahora por los recientemente electos como representantes del PRD.

\subsection{Lo cívico y lo popular}

Una manifestación particular de lo cívico fue la adoptada por el movimiento campesino comandado por Genaro Vázquez antes de involucrarse en la vía armada, es decir, la "Asociación Cívica Guerrerense". Ésta practicaba la lucha cívica de masas, la cual incluía la participación en los procesos electorales. Esa lucha de masas era cívica porque se desarrol ló por vías pacíficas y legales. Lo novedoso de esta vía fue que incluyó el recurso el ectoral en un periodo y contexto en que la izquierda mexicana lo rechazaba por considerar que implicaba hacerle el juego a la burguesía. (Recuérdese el término "la farsa electoral" todavía socorrido por grupúsculos de la ultraizquierda). Una derivación de este grupo fue la "Asociación Cívica Nacional Revolucionaria", que constituyó un movimiento político protopartidario, el cual posteriormente se fusionó en el PRD. En su estructura orgánica, los "comités cívicos de base" y los "comités cívicos de lucha" eran los grupos fundamentales de apoyo. Como es claro, en este caso, Io "cívico" es lo el ectoral asociado a un movimiento social de corte campesino y a otro semipartidario (ACNR, Declaración de principios).

\subsection{Ciudadanía y movimientos reivindicativos}

La tercera variante mexicana de lo ciudadano es la vinculada a los movimientos autónomos en torno a la educación, salud, conflictos laborales, condiciones materiales de vida en la ciudad, situación de la mujer, etcétera; es decir, los protagonizados principalmente por el magisterio, los médicos, los trabajadores, los colonos urbanos, feminis- 
tas, etcétera. En conjunto, las presiones ejercidas por estos movimientos independientes de corte sindical, popular y de género lograron avances en la materialización de los derechos sociales ya reconocidos en la Constitución. Sin abandonar su dimensión reivindicativa, se están descubriendo como sujetos de derechos y, en esa misma medida, adquiriendo perfiles ciudadanos. Por ello, cada vez con mayor frecuencia y claridad, se califican a sí mismos como tales. En este contexto, los sociólogos urbanos en particular, a contracorriente de las consideraciones usuales que vinculan la ciudadanía con la nación, detectaron que "la conquista de los plenos derechos ciudadanos en las ciudades... ha sido tardía; es decir, hay carencia de una amplia participación política ciudadana en la toma de decisiones sobre la organización de las ciudades" (Alabart, et al. 1994, 15). Por ello, J . Borja sostiene lacónicamente que "ciudadano es aquél que participa en la conquista de la ciudad" (Borja, 1990). Los grupos, organizaciones y movimientos sociales que intervienen en dicha conquista acceden, al mismo tiempo, a una ciudadanía "secundaria" que el sistema les negaba, de facto, al ser excluidos de las decisiones urbanas (Reilly, Ch. A., 1994, 2, 316 y 321; Kowarick, L., 1991; Schteingart, M., 1991). Por la composición social de los integrantes de estos movimientos, se aludía también al acceso a una ciudadanía "popular". Obviamente, en estos casos, la ciudadanía "urbana" está asociada tanto a la reivindicación colectiva de satisfactores sociales (vivienda, servicios urbanos, etcétera), como al ejercicio de derechos políticos (participación en las decisiones urbanas) por parte de los sectores populares urbanos. La diferencia entre esta experiencia y la vivida por las Asociaciones Cívicas recién aludidas estriba en que sus integrantes toman conciencia de sus derechos sociales y políticos después de participar en luchas reivindicativas y en que se involucran en las contiendas electorales más tardíamente.

\subsection{Movimiento en defensa de los derechos humanos}

Este movimi ento lucha por la defensa y reconocimiento de derechos cívicos y políticos fundamentales. Entre el los destacan las demandas por la supresión de la tortura, aplicada a los acusados, y de la represión 
utilizada por el Gobierno con la población y asimismo contra el abuso de las autoridades. Pugna por la presentación de los desaparecidos, la libertad de los presos políticos, a favor de los perseguidos y exiliados políticos, por el castigo a los represores y por las libertades políticas. Lucha por limitar la impunidad a las autoridades infractoras de los derechos humanos y por obligarlas a reconocer y respetar los derechos que asisten a las víctimas (Gallardo, L.R., 1992).

Los agrupamientos defensores de los derechos humanos no conforman un movimiento sectorial, sino una red de movimientos. Porque a la lucha por estos derechos se adhieren no sólo un número amplio de comisiones, academias, centros, ligas, coordinadoras y organismos específicos, sino también diferentes grupos sociales del campo y la ciudad, así como numerosas ONGs, miembros de partidos políticos y de diferentes confesiones religiosas, así como la opinión pública. Como es daro, en este caso las dimensiones de la ciudadanía que son objeto de defensa son la civil y la política.

\subsection{Ciudadanía y defensa del voto}

La experiencia ciudadana reciente y más importante, desde 1988 a la fecha, es la constituida por los grupos surgidos en torno a los procesos electorales. Están integrados no sól o por agrupaciones específicas para tal objeto, sino también por diferentes agrupamientos reivindicativos y organizaciones civiles, así como por miembros de partidos políticos, organismos no gubernamentales (ONG) y miembros de Comunidades E desiales de Base (CE B). Su orientación ideológica conforma un abanico amplio que incluye tanto la llamada izquierda, como la derecha. Luchan por rescatar y hacer valer la dignidad ciudadana, como origen y fundamento del poder político, y pugnan por el respeto a los derechos, especialmente los políticos. Tiene como objetivos principales la educación cívica, así como la defensa del voto y de los resultados electorales, a través de la observación y vigilancia de los comicios. Ellos han dado lugar recientemente a movimientos cívicos de masas. Evidentemente, aquí lo cívico o ciudadano consiste en la defensa del derecho político fundamental a participar en las elecciones. 
A partir de las cinco experiencias anteriores, es daro que en la versión mexicana de la ciudadanía destacan dos particularidades: por una parte, la articulación entre su vivencia individual y la colectiva y, por la otra, la relación entre la ciudadanía primaria y la secundaria. La vinculación entre la dimensión individual y la grupal es tal que parece llegar a prevalecer incluso la primera sobre la segunda. Porque la influencia liberal y la democrática, ya aludidas, que establecen una ecuación de igual dad entre un ciudadano y un voto, y que privilegian la vivencia individualista de su ciudadanía, está más vigente entre sectores acomodados de la sociedad. Pero segmentos activos de las capas medias y populares poseen de la ciudadanía una experiencia, al mismo tiempo, colectiva. A través de víncul os asociativos participan tanto en grupos ciudadanos semipartidarios y en comités cívicos integrados en movimientos sociales (campesinos o urbanos) como en movimientos a favor de los derechos humanos o movimientos cívicos o ciudadanos defensores del voto. De forma similar (por supuesto, no idéntica) a como los grupos étnicos se integran a la comunidad nacional (es decir, se hacen "ciudadanos) no individualmente, sino en cuanto grupalidades, los mexicanos están descubriendo y practicando su ciudadanía al participar, formal o informalmente, en grupos y movimientos ciudadanos.

La segunda particularidad de estas experiencias es calificar la ciudadanía ganada por los sectores mayoritarios, especial mente de las ciudades, como "secundaria o popular". Estos dos calificativos no implican asentar la existencia de varias categorías de ciudadanía. Pero permiten enfatizar que esos sectores están accediendo a ella mediante la movilización social y con notable retraso respecto al reconocimiento formal de la ciudadanía "primaria" por parte del Estado. Ésta la han conquistado y hecho efectiva a través del aprendizaje y práctica de la "secundaria", interviniendo en sus reivindicaciones respectivas y en la resolución democrática de sus asuntos internos.

Cabe, pues, inferir que en México existen movimientos ciudadanos por la defensa del voto y movimientos sectoriales que articulan demandas particulares con la conciencia de derechos y que, por ello, actúan ciudadanamente; es decir, intervienen como ciudadanos no sól o cuando defienden el voto y se convierten en observadores electorales, sino 
también cuando presionan por sus derechos civiles y sociales. De acuerdo con las dimensiones de la ciudadanía analizados por Marschall, en conjunto estos movimientos reivindican tanto la ciudadanía social, como la civil y la política.

\section{La respuesta gubernamental a la ciudadanía emergente}

Los análisis socio-políticos mexicanos no suelen resaltar la otra cara de la corporativización de que ha sido objeto. La sociedad mexicana, es decir, el relegamiento que han sufrido los valores y prácticas ciudadanas tanto por parte del gobierno, como de la propia sociedad civil. Durante el periodo posrevolucionario, la idea que predominó entre la clase gobernante acerca de la ciudadanía fue burocrática. El civismo era un simple "recordatorio de los vínculos administrativos entre el Estado y las personas" (Monsiváis, C., 1988, 386). Y la "participación ciudadana un simple acto de asentimiento al régimen" (Loaeza, S., 1981, 29). Para el Estado mexicano, el "buen ciudadano" era el contribuyente que pagaba con puntualidad y exactitud los impuestos, el que era respetuoso del gobierno y no ponía en cuestión sus acciones ni las enjuiciaba, y el que participaba en los actos de adhesión al sistema y lo apoyaba en los procesos electorales. El resultado final era una sociedad civil débil y una ciudadanía mediatizada, con un margen muy reducido de vida propia y, en buena medida, subordinada al Estado.

Esta tendencia básica se mantuvo hasta el sexenio de $M$. de la Madrid, en el que el gobierno intentó abrir la sociedad y la vida política a las formas ciudadanas. Esta apertura consistió en ensayos por descorporativizar la vida política y por ciudadanizar la organización de la sociedad. Del segundo tipo fueron los intentos por crear agrupamientos ciudadanos integrados al gobierno (UNE, Movimiento Ciudadano, etcétera). En el terreno electoral, tras el fracaso del PRI en Chihuahua en los ochenta, el gobierno puso fin al experimento de ciudadanizar la política. Sin embargo, la presión y movilización sociales, el deseo de intervenir en la toma de decisiones, el interés por defender el derecho al voto y por garantizar procesos electorales menos inequitativos y más competitivos fueron creando un clima más ciudadano y motivaron 
varias reformas administrativas y electorales durante el sexenio de $C$. Salinas. Mediante las primeras, algunos consejos, comités, etcétera, de instancias gubernamentales (de Protección Civil, de Seguridad, de Planeación y Procuraduría U rbanas, de Contraloría social, etcétera) se abrieron a la intervención de ciudadanos no involucrados en partidos políticos para que se integraran a ellos. Ello implica que formalmente comienza a existir presencia ciudadana en estas instancias. Pero con frecuencia son incorporados a estos órganos ciudadanos que habían participado previamente como funcionarios públi cos o habían tenido nexos con el Partido oficial. Es decir, se advierte una contracción entre la apertura ciudadana formal y la práctica todavía clientelar y corporativa.

Parte de las reformas el ectorales recientes consistieron en nombrar consejeros ciudadanos en el IFE con la propuesta y aprobación de los partidos. Este relativo avance coexistió con la creación, desde arriba, de movimientos ciudadanos vinculados al régimen, así como de grupos de observadores paralelos a los autónomos.

Lo anterior manifiesta que, a causa de la presión social, el Estado se ve impulsado a institucionalizar relaciones y procedimientos normativos con ciudadanos y ya no tanto con corporaciones clientelares. Como respuesta, el gobierno abre, de manera calculada, las puertas a la intervención ciudadana, estableciendo, al mismo tiempo, contrapesos que le permitan mantener el control del proceso de ciudadanización. Y, a contrapelo de su proyecto inicial, el régimen de C. Salinas realizó reformas electorales. Éstas, sin embargo, no resuel ven el paso de una sociedad mediatizada y corporativizada a otra de ciudadanos, ni tampoco la urgente reforma del Estado.

\section{Conclusiones}

El análisis realizado permite establecer tres tipos de conclusiones básicas:

1. La ciudadanía es una conquista y el resultado de múltiples luchas. Y tan ciudadana es su dimensión civil como la social y la política. En sus 
elementos constitutivos se mezclan influencias ideológicas difíciles de compatibilizar como la li beral, la democrática y la socialista. Por otra parte, la situación de ciudadano constituye un derecho real pero, asimismo, un modelo y un proyecto ideales $y$, en buena parte, no materializados. Su cristalización exige del Estado la intervención directa para avanzar en la consecución de los derechos sociales y, por el contrario, la no interferencia y respeto a los márgenes de acción independiente de los individuos y de la sociedad, en el caso de los civiles y políticos. Hoy cabe sostener la existencia de derechos culturales y ecológicos.

2. Las experiencias mexicanas de la ciudadanía se dan tanto en el terreno civil como en el social y político. Durante muchos años las reivindicaciones sociales se llevaron a cabo sin que hubiera una vinculación explícita con la conciencia de derechos, en este caso, sociales. Esta situación se está modificando crecientemente. Hoy los mexicanos son más sensibles a la dimensión política de la ciudadanía y, en particular, a la relacionada con la defensa del voto y de los resultados el ectorales. EI movimiento por derechos humanos, principal defensor de la vertiente civil de la ciudadanía, está incrementando la conciencia acerca de ella. Y en la experiencia mexi cana de la ciudadanía se articula la vivencia individual con la grupal. Estos factores básicos deben ser relacionados con los rasgos aun corporativos de la cultura política predominante. Ambos son reales. Perotendencialmente los perfiles corporativos están perdiendo fuerza; y los rasgos ciudadanos se incrementan, aunque entre sectores reducidos de la población.

3. Durante el periodo posrevolucionario, el Estado mexicano impulsó la materialización de los derechos sociales, pero con resultados muy desiguales y favoreciendo a sectores vinculados al partido oficial (burocracia, movimientos oficialistas, etcétera). La concepción gubernamental de la ciudadanía es burocrática y limita, de facto, el desarrollo de los derechos civiles y políticos. Por ello, México es un país con vida ciudadana aún débil y con un proceso de ciudadanización mediatizado por el gobierno. Éste se inclina ahora por impulsar una sociedad de ciudadanos 
que sean electoralmente apoyadores del sistema, es decir, más sumisos que reales interlocutores y enjuiciadores del gobierno. Por esta razón, sus medidas oscilan entre el model o ciudadano y el corporativo.

Para la evolución ciudadana del país aparecen dos salidas esperanzadoras. Por una parte, los avances ya logrados y que, de manera crecientemente autónoma, combinan la conciencia de su dimensión individual con la vivencia plural y colectiva de su defensa. $Y$, por otra, Ios reclamos crecientes por modificar las relaciones entre estado sobre la base de una complementariedad sin subordinación.

\section{Bibliografía}

1 A labart, A., García, S. y Giner, S. (Comp.) Clase, poder y ciudadanía, Siglo XXI, España, 1994.

2 Alonso, J. (Coord.), Cultura política y educación cíviç@ IIH-M.A. Porrúa, 1994.

3 A min, S. Le grand tumulte? Les mouvements sociaux dans l'economie-mondeParis, La D ecouverte, 1991.

4 A rendt, N ., "Los derechos públicos y los intereses privados", en M. Mooney y F. Stuber (Comp.), Los humanistas y la política México, FCE, 1984.

5 A ron, A. "Is multinational citizenship possible?", en Social Research, Vol. 41, 1974.

Ensayo sobre las libertadesC onaculta, A lianza, México, 1991.

6 Barbalet, J. M. Citizenship, rights, struggle and class inequality, Minneapolis, University of Minnesota Press, 1988.

7 Bendix, R. Estado nacional y ciudadanía,A morrortu, Buenos Aires, 1973.

8 Borja, J. "H acia la ciudad democrática", en La Jornada Semanal N o. 34, 4 de febrero, 1990, pp. 23-27.

9 Borón, A. "Estado, democracia y movimientos sociales", en Memoria, Cemosv 0. 54, mayo 1993.

10 Butel, M. y Lasime, M. "Mañana, no más Estado sino una empresa mundial", en L'A utre JournallN 0. 14, julio-agosto, 1991.

11 Cohen, J. y A rato, A. "Pluralismo y participación.

Reconstrucción del concepto de sociedad civil", en suplemento de Cultura, El N acional, 26 de enero de 1993. 
Bibliografía
7 Escalante, G.F. Ciudadanos imaginariosEl Colegio de México, México, 1992.

Reseña a H irschman, Retóricas de la intransigenciaFCE, México, 1991, en Estudios SociológicoßX, 1992.

8 Gallardo, R. "Los derechos humanos: nuevo campo de la lucha social en México", en Alonso, J., A ziz, A. y Tamayo, J., El N uevo Estado mexicana N ueva Imagen, México, 1992, pp. 225-273.

9 Giroux, H. A. La escuela y la lucha por la ciudadanía Siglo XXI Ed., 1993.

10 Heller, A. "Ética ciudadana y virtudes cívicas" en A. Heller y F. Feher, Políticas de la postmodernidacBarcelona, Península, 1989.

11 Jelin, E. Ciudadanía e identidad CLAC SO , Buenos Aires, 1989.

12 Kowarick, L. "Ciudad y ciudadanía", en N ueva Sociedad N 0. 114, julio-agosto, 1991.

13 Lafer, A. La reconstrucción de los derechos human, $₫ E E$, México, 1994.

14 Lipset, S. M. "Introduction” a Marschall, T. H., O .C., pp. v-xx.

15 Loaeza, S. "El laberinto de la pasividad", en N exos N 0.48, diciembre 1981.

16 Lyotard, J-F. La diferencia Gedisa, Barcelona, 1991, pp. 167171.

17 Madrazo, J. y Beller, W. “D erechos humanos y participación so cial", en M. E. Vázquez N ., Participación ciudadana y control social, M. A. Porrúa, México, 1994.

18 Marschall, T. H. Class, C itizenship and Social Development Greenwood Press, W estport, Connecticut, 1976.

19 Monsiváis, C. "N otas sobre la cultura política en México", en Cordera, R. et. al., México, el reclamo democrátiç,iglo XXIILET, México, 1988.

20 Moulin, C. J. El Estado y el ciudadano A guilar, Madrid, 1967.

21 PRD, "Memoria del Taller N acional del Movimiento Ciudadano", 22-24 de abril, Chapala, 1994, 24 Págs.

22 Reilly, Ch. A. N uevas políticas urbanasA rlington, Virginia, E.U., 1994.

23 Reyes Heroles, J. El liberalismo mexicano México, FCE, 1982, 3 Vols.

24 Rosaldo, R. "Identity, conflict and evolving latino-communities: Cultural Citizenship in San Jose, California", mimeo.

25 Schteingart, M. "Autogestión urbana y derechos ciudadanos", en N ueva Sociedado O.C. 
Bibliografía
26 Somers, M. R. "Citizenship and the place of public sphere", en American Sociological Review1993, Vol. 58, octubre, pp. 587620.

27 Steenbergen, B. van (Ed.), The condition of citizensh,j§age, Londres,1994.

28 Touraine, A. Critique de la modernitł,ayard, París, 1992.

29 Valadés, D. "La revolución social mexicana y las transformaciones constitucionales", en Varios: México. 75 años de revoluciónPolítica, I, México, IN ERM-FCE, 1988, pp. 25-49.

30 Villegas, A. El liberalismo, México, UN AM, 1986.

$31 \mathrm{~W}$ allerstein, I. The politics of the world economy. The States, the movements and the civilization $\subseteq$ ambridge, Editions de la Maison de Sciences de l'homme, 1984.

32 W olin, S. S. Política y perspectivaA morrurtu, Buenos Aires, 1993, p. 91. 


$$
\bullet \bullet
$$

